\title{
ДОЛГОВОЕ ФИНАНСИРОВАНИЕ КАК ФАКТОР ПОВЫШЕНИЯ УСТОЙЧИВОСТИ ФИНАНСОВОЙ СИСТЕМЫ РЕГИОНА
}

\author{
(c) 2021 Киселева Елена Григорьевна \\ кандидат экономических наук, доцент Высшей школы управления и бизнеса \\ Санкт-Петербургский политехнический университет Петра Великого, Россия, Санкт-Петербург \\ E-mail: chachina_eg@spbstu.ru \\ https://orcid.org/0000-0002-6334-5562 \\ (c) 2021 Путихин Юрий Евгеньевич \\ кандидат экономических наук, доцент \\ Финансовый университет при правительстве РФ, Россия, Санкт-Петербург \\ E-mail:spb_mail@fa.ru \\ https://orcid.org/0000-0002-4918-5000
}

В статье проведен сравнительный анализ инвестиционной активности в России с более подробной детализацией этого процесса на примере второй по величине российской агломерации округов - регионах Северо-западного федерального округа. База исследования - открытые данные Федеральной службы государственной статистики. В качестве методов исследования используется методы сравнения и группировки, индексный метод. На базе анализа статистических показателей, характеризующих инвестиционный процесс, а также системы индикаторов, предложенной авторами выявлено соответствие средней динамики показателей инвестиционной активности РФ и регионов СЗФО на фоне высокой степени дифференциации значений индикаторов внутри регионов. Уровень инвестиций в основной капитал в ВРП по регионам СЗФО на 5-7\% выше значения показателя в целом по РФ за сопоставимый период. Повышенный уровень инвестиционной активности выявлен у города Санкт-Петербурга и Ленинградской области. Псковская область характеризуется самой низкой инвестиционной активностью среди регионов СФЗО в сочетании с высоким уровнем государственного долга и кредитного риска. Результаты исследования также показали, что средний темп роста инвестиции в основной капитал в РФ за период с 2010 по 2020 гг. более чем в два раза ниже значений этого показателя в предшествующее десятилетие, что говорит о снижении инвестиционной активности и замедлении экономического роста. Сопоставление результатов индикативного анализа инвестиционной деятельности в регионах СФЗО и эконометрических исследований российских и зарубежных ученых, изучающих вопросы взаимосвязи уровня инвестиций и экономического роста развивающихся стран, позволило сделать вывод о необходимости изменения государственной долговой бюджетной политики в части финансирования инвестиционных расходов субъектов РФ с использование механизма инвестиционного государственного кредита, эффективность которого имеет высокую степень научной обоснованности.

Ключевые слова: инвестиции, инвестиционная активность, индикаторы, долговое финансирование, бюджетная политика, экономический рост, регионы СЗФО

Благодарность. Статья подготовлена в рамках научно-исследовательской работы «Обеспечение устойчивости финансовой системы региона: механизм, инструменты, показатели оценки», регистрационный номер VTK-GZ-PNIR -43-21.

\section{ВВЕДЕНИЕ}

Инвестиционная активность российских предприятий сегодня во многом определяет состояние и перспективы развития страны завтра. Анализ региональной финансовой системы, как обобщение результатов участников предпринимательской деятельности, позволяет увидеть текущее состояние инвестиционной активности, а также перспективы экономического роста. Инвестиции являются важным фактором повышения конкурентоспособности экономики страны, без надлежащего уровня инвестиций в основной капитал невозможен экономический рост $[1,2,3]$. Экономический рост в свою очередь выступает главным экономическим принципом института благосостояния, реализация которого обеспечи- 
вает высокий уровень и качество жизни населения [4, с. 321]. На инвестиционную активность региональных предприятий влияет не только спрос на выпускаемую продукцию или предоставление налоговых инвестиционных льгот, но и доступность заемных средств, в том числе с использованием механизмов государственного кредитования. Уровень инвестиционной активности регионов РФ является следствием реализации инвестиционного потенциала, а также определяется характеристиками инвестиционного климата в стране [5, 6].

Анализ динамики показателей инвестиционной активности РФ

Как было отмечено ранее, уровень инвестиционной активности в стране является производной от уровня инвестиционной активности субъектов РФ и отражает динамику инвестиционного процесса в целом. Поэтому анализ показателей инвестиционной активности необходимо рассматривать с использованием обобщения тенденций в целом на фоне исследования динамики отдельных субъектов РФ. Это позволит дать более всестороннюю картину и повысит базу сравнительных оценок.

Одним из базовых показателей в оценке инвестиционной активности в российской и международной практике аналитических оценок традиционно служит уровень инвестиций в основной капитал, который отражает вложения различных групп инвесторов в основные производственные фонды. В таблице 1 приведена динамика данного показателя с учетом источников финансирования. Анализ данных таблицы позволяет сделать следующие выводы:

- размер инвестиций в основной капитал в России начиная с 2000 года имеет тенденцию к умеренному росту. Средний темп роста инвестиций за период с 2000 по 2019 год составляет 18,5\%. Вместе с тем в течение последних девятнадцати лет присутствуют два года, которые демонстрируют динамику нехарактерную для общего ряда: в 2009 году произошло снижение показателя (темп роста 90\%), в 2015 году изменение показателя незначительно (темп роста 101\%). При этом темп роста инвестиций в основной капитал за последние 10 лет имеет тенденцию к замедлению: так средний темп роста в период с 2010 по 2019 год составляет $10 \%$, при значении показателя $26 \%$ за период с 2000 по 2010 гг.;

- если рассматривать структуру финансирования инвестиций в основной капитал, то можно с уверенностью сказать, что для российской экономики характерно использование в качестве источника инвестиции собственных и привлеченных средств в равной степени. При этом с 2008 по 2010 гг. наблюдается незначительный сдвиг в структуре финансирования в пользу преобладания доли привлеченных средств (в 2008 году 40\% собственные средства, 60\% заемные), при этом в результате постепенного снижения доли привлеченных средств в 2016 году соотношение возвращается к прежней структуре (51\% собственные средства, $49 \%$ заемные средства).*

- в привлеченных средствах преобладают бюджетные средства, в которых учтены средства федерального бюджета и региональных бюджетов субъектов РФ. Также можно отметить, что с 2010 по 2015 год наблюдалась тенденция к умеренному росту федерального финансирования с 6\% до 11\%, которая изменилась с 2016 года в сторону увеличения использования средств местных бюджетов и бюджетов субъектов РФ. На втором месте по величине источников финансирования инвестиционной деятельности в составе привлеченных средств находятся кредиты банков, их удельный вес за девятнадцатилетний период варьируется от $3 \%$ до 11\%. Средства государственных бюджетных фондов, средства организаций и населения на долевое строительство традиционно имеют незначительный удельный вес в составе привеченных средств. Средства от эмиссии акций и выпуска корпоративных облигаций составляют менее $3 \%$.

- сравнивая уровень инвестиционной активности России и других стран можно заключить, что уровень инвестиций в основной капитал в РФ сопоставим с уровнем инвестиционной активности стран Европы с умеренным ростом экономики (прирост ВВП 2-4\%). Для сравнения в 2018 году в Китае величина показателя составляет 42,3\%, Катар - 44,8\%, Алжир - 42\%, Южная Корея $-29,3 \%$, Индия $-27,6 \%$, Франция, Япония $-22 \%$, Германия $-20 \%$, США - 17\%, Италия $-16,5 \%$, Бразилия $-15,8 \%$ ***

\footnotetext{
* Инвестиции в основной капитал по источникам финансирования / Федеральная служба государственной статистики, 2021. [Электронный ресурс]. URL: https://rosstat.gov.ru/investment_nonfinancial (дата обращения 08.03.2021)

** Николаев А.И., Марченко Т.Е., Точилкина О.С.Инвестиции как источник экономического роста // Аналитический доклад, Институт стратегического анализа.-М., 2019.- 27c. URL: https:/www.fbk.ru/upload/docs/ Investments_report.pdf(дата обращения 10.03.2021).
} 


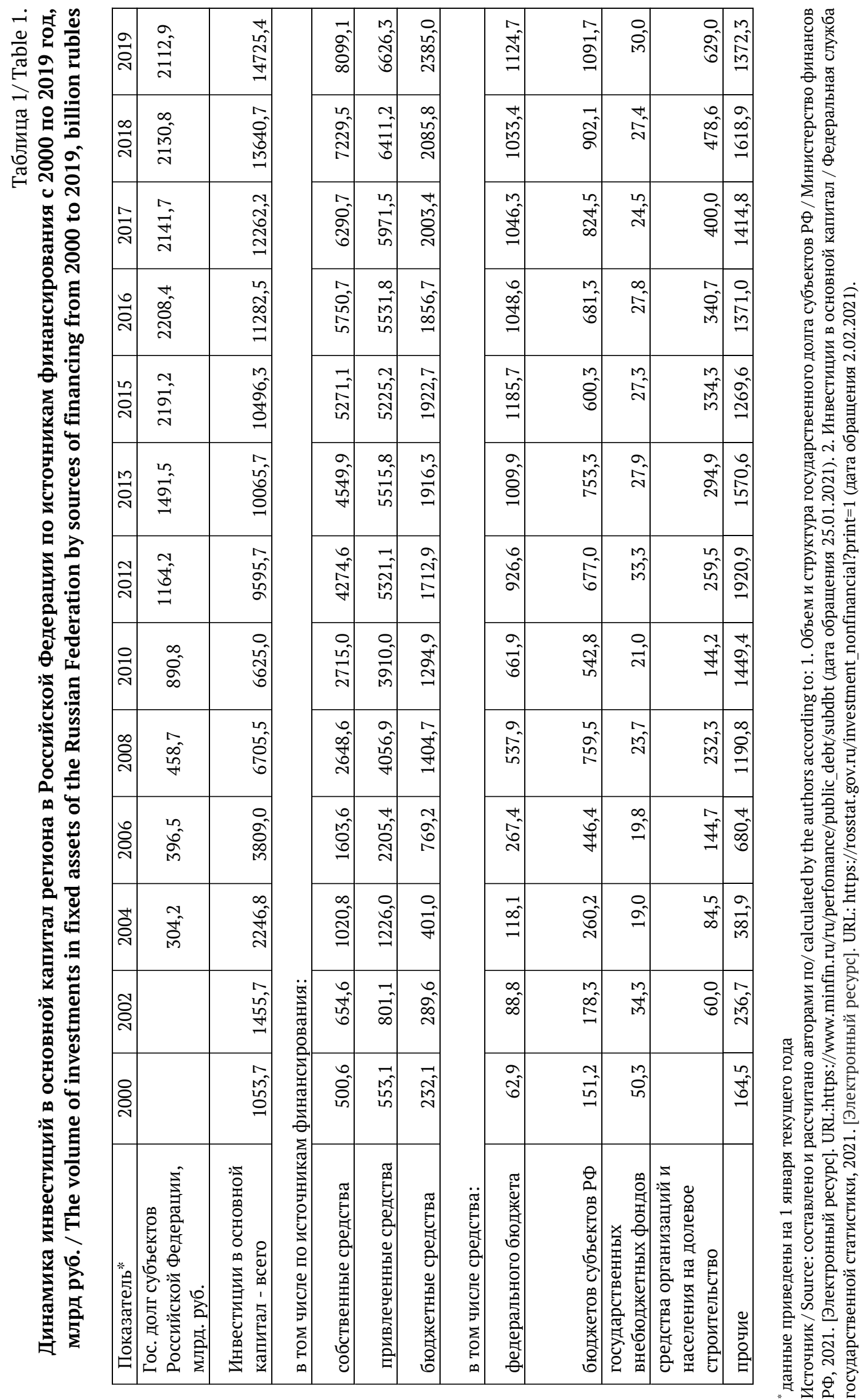


АНАЛИЗ ИНДИКАТОРОВ ИНВЕСТИЦИОННОЙ АКТИВНОСТИ РФ

Наряду с абсолютными показателями, характеризующими уровень инвестиционной активности важную роль для характеристики инвестиционного процесса в стране играют относительные индикативные показатели, отражающие сопоставление уровня инвестиций в экономике с другими макроэкономическими показателями. Традиционно рассчитывают следующие показатели инвестиционной активности: доля инвестиций в ВВП, уровень инвестиций на душу населения, коэффициент износа основных средств и другие. Расчет и анализ индикаторов инвестиционной активности позволяет провести более глубокий анализ, расширить аналитику исследуемой темы, сопоставить индикаторы между собой и сравнить уровни инвестиционной активности разных по уровню размера экономики стран. Индикаторы инвестиционной активности приведены в таблице 2 . Анализируя показатели таблицы можно сделать следующие выводы:

- положительной тенденцией является умеренный рост уровня инвестиции в основной капитал на душу населения. В среднем за последние 20 лет показатель имеет тенденцию к умеренному росту, демонстрируя снижение в 2009, 2015 и 2019 гг. Средний темп роста этого показателя за период с 2000 по 2019 гг. составляет $14,7 \%$, темп роста в первое десятилетие XXI века - 16\%, с 2010 по 2019 год - 7,6\%.

- негативным моментом является не соответствие темпа роста инвестиций в основной капитал и темпа роста инвестиций на душу населения: средний темп роста инвестиций на душу населения заметно ниже темпа роста инвестиций в основной капитал. По валовому накоплению основного капитала на душу населения Россия уступает развитым странам, при этом находится на уровне развивающихся стран, таких как Аргентина и Бразилия. Показатели России ниже показателей Германии в 5,5 раза, Великобритании в 5,8 раза, США в 8,1 раза, Франции в 6,1 раза, Японии в 6 раз, Канады в 7 раз [7, с. 16].

- доля инвестиций в основной капитал в
ВВП с 2011 года в среднем составляет 20,5\% и не подвержена значительным колебаниям. При этом, самостоятельные расчеты, проведенные автором, говорят о небольшой завышенности показателя, представленного в открытых источниках. При расчете показателя автор использовал ВВП в сопоставимых ценах и полученное среднее значение составляет $17 \%$, т.е. на $3,5 \%$ ниже.

При этом необходимо отметить, что «майскими указами» президента была предусмотрена разработка мер, направленных на увеличения этого показателя до 25\% в 2015 году, и до $27 \%$ в 2018 году.*'Однако целевой уровень достигнут не был. Уровень инвестиционной активности в российской экономике сопоставим с уровнем инвестиционной активности развивающихся стран и стран Еврозоны. Так, например, по темпам прироста инвестиций в 2017 г. Россия находилась между Сьерра-Леоне и Зимбабве, что также сравнимо с темпами роста инвестиций в основной капитал Великобритании (4\%), Норвегии и Австрии (по 4,9\%) [7].

- степень износа основных средств РФ стабильно находится на уровне $45 \%$, при этом также, как в случае с показателем инвестиций в основной капитал, колеблемость показателя мала. Можно отметить стабильность показателя, т.е. отсутствие существенных изменений его значений за последние 20 лет. Средний срок службы основных средств, соответствующий подобному значению показателя, 20 лет. Если для категории основного капитала «здания и сооружения» подобный возраст вполне допустим, то для машин и оборудования он является критическим, чем ниже степень износа машин и оборудования, тем более качественную и конкурентоспособную продукцию выпускают предприятия. Сопоставляя значения показателей можно прийти к выводу, что несмотря поддержание определенного уровня инвестиций в основной капитал перекрывается лишь минимально необходимая потребность в инвестициях. Здесь же стоит заметить, что степень изношенности основных фондов по странам БРИКС составляет 35\%, по странам ЕС -30\%, США - 15\% [7, 8].

\footnotetext{
* Указ Президента Российской Федерации 7 мая 2012 года № 596 «О долгосрочной государственной экономической политике». URL: http://www.consultant.ru/document/cons_doc_LAW_129343
} 


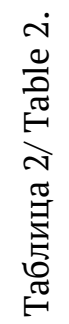

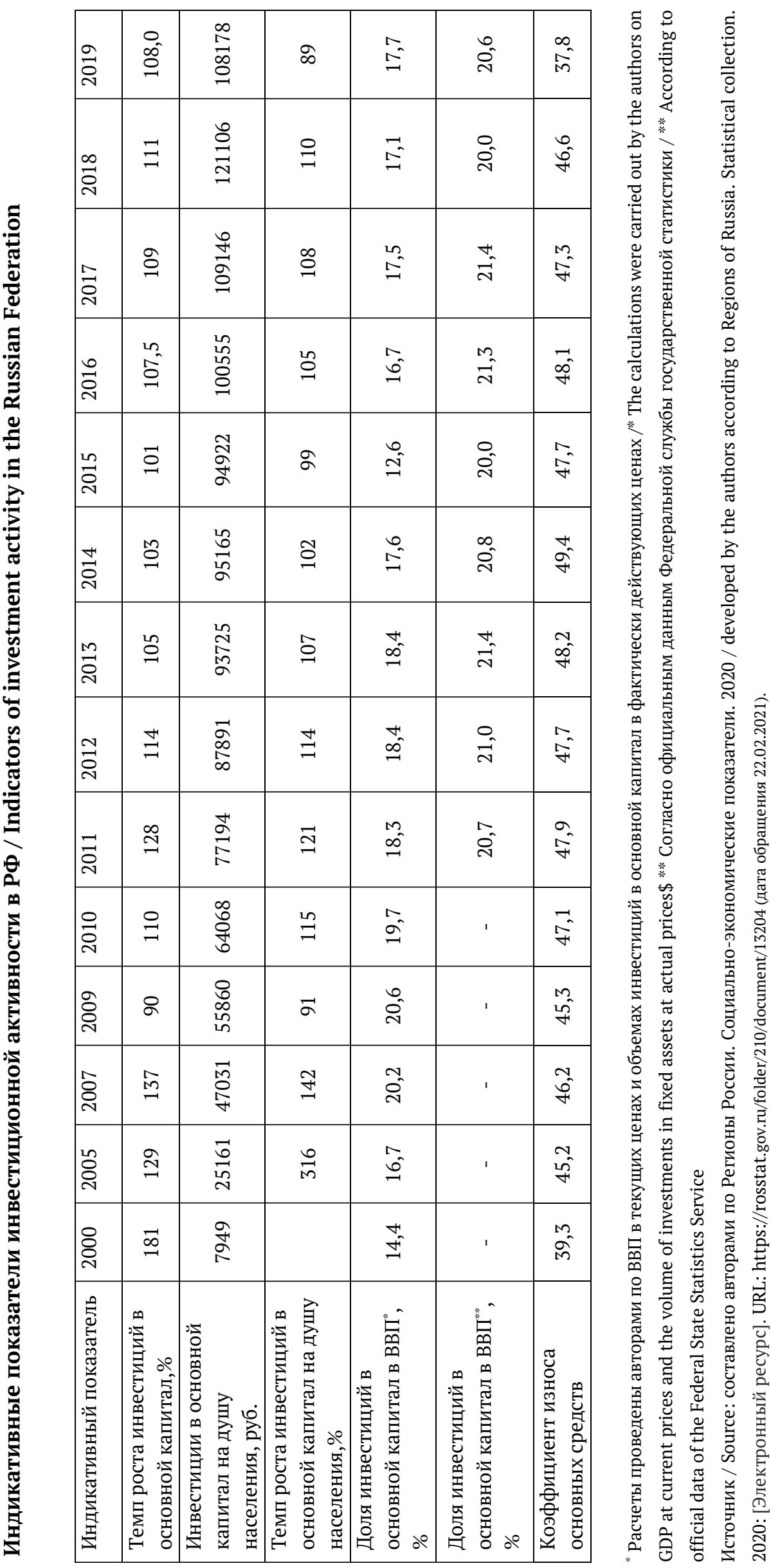




\section{АНАЛИЗ ИНВЕСТИЦИОННОЙ АКТИВНОСТИ РЕГИОНОВ СЗФО}

В качестве объекта исследования инвестиционной активности в субъектах Российской Федерации в статье выбран второй по уровню агломерации округ России, который имеет высокий уровень развития промышленности, транспортных, логистических и туристических услуг - Северо-западный федеральный округ (СЗФО). Исследуя динамику основных показателей инвестиционной активности в регионах СЗФО можно сделать следующие выводы:

- темпы роста инвестиций в основной капитал региона по регионам Северо-Западного федерального округа в среднем сопоставимы с темпами роста показателя по РФ (табл. 3). Так, средний рост показателя в РФ за последние 5 лет за период с 2014 по 2019 гг. составляет 7,3\%, по регионам СЗФО 8,2\%. В 2019 году произошло снижение объёма инвестиций в целом по региону СЗФО, в следствии снижения инвестиционной активности половины его субъектов. К субъектам, которым удалось сохранить уровень инвестиционной активности относятся Ненецкий автономный округ, Мурманская, Калининградская и Вологодская области. Предпосылки роста инвестиций и инвестиционного потен- циала в регионах СЗФО отмечались в исследованиях российских ученых [9, с.24]. В основу таких предпосылок закладывалась взвешенная региональной инвестиционная политика, в основе которой лежит преемственности Стратегий социально -экономического развития СевероЗападного федерального округа*.

- значительная дифференциация объёма инвестиций в основной капитал по регионам СЗФО. По величине показателя среди исследуемых регионов лидирует г. Санкт-Петербург и Ленинградская область, на них приходится от $40 \%$ до 50\% общего объема инвестиций в разные годы. Низкий уровень инвестиционной активности можно отметить в Псковской области, которая на протяжении многих лет стабильно находится на последнем месте по значению показателя. И это все несмотря на высокий уровень закредитованности. Так, в 2020 году показатель отношения долга к ВРП составляет 100\% по сравнению со средним уровнем в РФ 28,16\% [10, 11]. При этом Псковская область демонстрирует стабильный рост уровня инвестиций в расчете на душу населения, что в свою очередь, объясняется планомерным снижением численности населения. К субъектам с устойчивыми темами роста объема инвестиций в основной капитал

* Стратегия социально-экономического развития Северо-западного федерального округа на период до 2020 года: распоряжение Правительства Р Ф от 18 ноября 2011 № 2074-р / Правительство России. [Электронный реcypc]. URL: http://government.ru/docs/all/80011/ (дата обращения 23.03.2021).

Таблиц̧а 3 / Table 3.

Объем инвестиций в основной капитал по субъектам СЗФО, млн. руб./ The volume of investments in fixed assets by the Northwestern Federal District, million rubles

\begin{tabular}{|l|c|c|c|c|c|}
\hline Субъект РФ & 2015 & 2016 & 2017 & 2018 & 2019 \\
\hline Российская Федерация & 3578186 & 3795422 & 4241519 & 4998018 & 6093362 \\
\hline Северо-Западный федеральный округ & 1437479 & 1742374 & 1883300 & 2308914 & 2082965 \\
\hline Республика Карелия & 32738 & 34700 & 41568 & 48116 & 48260 \\
\hline Республика Коми & 169936 & 200261 & 134152 & 136474 & 121578 \\
\hline Архангельская область & 172221 & 169432 & 215493 & 198357 & 193157 \\
\hline $\begin{array}{l}\text { в том числе: } \\
\text { Архацкий автономный округ }\end{array}$ & 114503 & 85703 & 106578 & 91041 & 97035 \\
\hline Вологодская область & 57718 & 83729 & 108915 & 107316 & 96122 \\
\hline Калининградская область & 87114 & 114155 & 138282 & 153428 & 199288 \\
\hline Ленинградская область & 69015 & 89462 & 130398 & 159880 & 101408 \\
\hline Мурманская область & 225915 & 264213 & 337674 & 511164 & 420872 \\
\hline Новгородская область & 100418 & 85495 & 113269 & 155744 & 170856 \\
\hline Псковская область & 69336 & 78742 & 70832 & 61530 & 49828 \\
\hline г. Санкт-Петербург & 27363 & 27272 & 29267 & 31297 & 33623 \\
\hline
\end{tabular}

Источник/ Source: составлено авторами / developed by the authors. 
региона можно отнести Ленинградскую, Калининградскую, Архангельскую и Мурманскую область. Новгородская область демонстрирует планомерное снижение показателя, чем выделяется на фоне остальных субъектов.

Анализ индикативных показателей инвестиционной активности по регионам СЗФО (таблица 4, 5) позволяет сделать следующие выводы:

- темпы роста инвестиций на душу населения каждого региона сопоставимы с темпами роста инвестиций в целом по регионам СЗФО. Устойчивый прирост инвестиций на душу населения за последние 10 лет наблюдается в Республике Карелия, в Вологодской, Мурманской, Псковской области. К субъектам СЗФО с неоднородной динамикой показателя относятся Республика Коми, Архангельская область, Ненецкий автономный округ, Новгородская область, город Санкт-Петербург. Новгородская и Калининградская области демонстрирует поступательное снижение показателя;

- положительным моментом в инвестиционной активности субъектов СЗФО выступает большее значение показателя «доля инвестиций в основной капитал в ВРП». Уровень этого показателя колеблется в пределах от $20 \%$ до $25 \%$, что в среднем на 5-7\% выше значения показателя в целом по РФ за сопоставимый период. Больший вклад в значение показателя вносят Ненецкий автономный округ, Республика Коми, Калининградская и Ленинградская область. На послед- нем месте по величине показателя стабильно находятся Республика Карелия. Величина показателя города Санкт-Петербурга в целом ниже, чем в среднем по регионам СФЗО, с тенденцией к умеренному росту;

- положительной тенденцией также является планомерное снижение коэффициента износа основных средств по субъектам СФЗО, вследствие чего значение показателя снизилось до минимального в 2019 году (34,8\%), что на несколько процентов ниже, чем в среднем по РФ. При этом также можно отметить что степень износа основных средств за период с 2015 по 2019 гг. по регионам СЗФО ниже, чем в среднем по РФ. К регионам с высоким уровнем обновления основных средств можно отнести Ленинградскую, Калининградскую, Новгородскую область и город Санкт-Петербург. Однако большая часть субъектов СЗФО все же имеет больший коэффициент износа, чем в среднем по СЗФО. $\mathrm{K}$ регионам стабильно сохраняющим коэффициент износа в среднем $47 \%$ относятся Республика Коми, Вологодская область, Мурманская, Псковская области. Ненецкий автономный округ в 2018 и 2019 году существенно снизил объёмы инвестиций в основной капитал, что вызвало рост коэффициента износа. При этом Ненецкий автономный округ стабильно занимал первое место по инвестиционной активности в период с 2000 по 2010 гг. [12].

Таблица 4 / Table 4. Инвестиции в основной капитал на душу населения в фактических ценах, руб. / Investments in fixed assets per capita, rubles

\begin{tabular}{|l|c|c|c|c|c|}
\hline Субъект РФ & 2015 & 2016 & 2017 & 2018 & 2019 \\
\hline Северо-Западный федеральный округ & 103799 & 125563 & 135240 & 165371 & 149028 \\
\hline Республика Карелия & 51865 & 55213 & 66531 & 77573 & 78336 \\
\hline Республика Коми & 197456 & 234582 & 158626 & 163333 & 147304 \\
\hline Архангельская область & 146111 & 144824 & 185708 & 172549 & 169388 \\
\hline в том числе: & \multicolumn{5}{|l|}{} \\
\hline Ненецкий автономный округ & 2625864 & 1952758 & 2424050 & 2073217 & 2206852 \\
\hline Архангельская область без автономного округа & 50849 & 74358 & 97557 & 97061 & 87674 \\
\hline Вологодская область & 73245 & 96271 & 117161 & 130889 & 171198 \\
\hline Калининградская область & 70953 & 91162 & 131658 & 160138 & 100668 \\
\hline Ленинградская область & 127119 & 147986 & 187298 & 279196 & 226048 \\
\hline Мурманская область & 131399 & 112509 & 149909 & 207436 & 229419 \\
\hline Новгородская область & 112340 & 128222 & 116213 & 101974 & 83268 \\
\hline Псковская область & 42179 & 42330 & 45776 & 49435 & 53550 \\
\hline г. Санкт-Петербург & 92811 & 129176 & 126462 & 158893 & 138026 \\
\hline
\end{tabular}

Источник/ Source: составлено авторами / developed by the authors. 
官

\begin{tabular}{|c|c|c|c|c|c|c|c|c|c|c|c|c|c|c|c|}
\hline \multirow{4}{*}{ 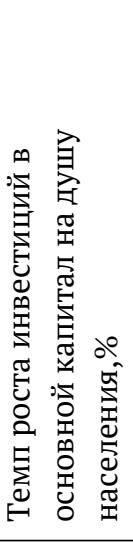 } & $\frac{\tilde{\rho}}{\vec{\rho}}$ & $\overrightarrow{8}$ & - & $\begin{array}{l}\tilde{\Omega} \\
\tilde{\Omega}\end{array}$ & $\underset{\infty}{\infty}$ & & : & $\begin{array}{l}m \\
\&\end{array}$ & $\begin{array}{l}\infty \\
\text { 今. } \\
\text { mat }\end{array}$ & فे & $\stackrel{0}{\stackrel{0}{\infty}}$ & $\begin{array}{l}0 \\
0 \\
\Xi\end{array}$ & $\hat{\bar{\infty}}$ & 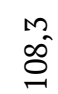 & $\begin{array}{l}\hat{\sigma} \\
\hat{\infty}\end{array}$ \\
\hline & $\stackrel{\infty}{\stackrel{\sim}{\sim}}$ & $\begin{array}{l}\text { a } \\
\text { Î }\end{array}$ & $\begin{array}{l}0 \\
\mathscr{0}^{-} \\
=\end{array}$ & $\begin{array}{l}\stackrel{0}{\mu} \\
\stackrel{0}{0}\end{array}$ & $\begin{array}{l}\hat{\sigma} \\
\text { aे }\end{array}$ & & $\begin{array}{l}\text { in } \\
\text { in }\end{array}$ & $\begin{array}{l}20 \\
\sigma\end{array}$ & $\stackrel{\Xi}{\exists}$ & $\begin{array}{l}0 \\
\stackrel{-}{I}\end{array}$ & $\vec{a}$ & $\begin{array}{l}+ \\
\text { on } \\
\stackrel{m}{n}\end{array}$ & 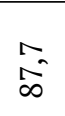 & 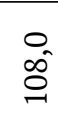 & $\begin{array}{l}0 \\
\stackrel{\text { In }}{\text { In }}\end{array}$ \\
\hline & 공 & 今ે & $\begin{array}{l}\text { ñ } \\
\text { ô }\end{array}$ & $\begin{array}{l}0 \\
\text { si }\end{array}$ & $\begin{array}{l}\text { No } \\
\text { ָे } \\
\text { - }\end{array}$ & & $\overrightarrow{\stackrel{A}{\Xi}}$ & $\stackrel{\sim}{\sim}$ & $\vec{A}$ & \begin{tabular}{l}
$\stackrel{H}{J}$ \\
\multirow{H}{*}{}
\end{tabular} & $\begin{array}{l}0 \\
\text { o. } \\
\stackrel{]}{-1}\end{array}$ & $\stackrel{\text { ले }}{\stackrel{M}{-}}$ & $\begin{array}{l}0 \\
8\end{array}$ & 옹 & $\begin{array}{l}\hat{s} \\
\hat{s}\end{array}$ \\
\hline & $\stackrel{0}{\stackrel{1}{\curvearrowright}}$ & $\begin{array}{l}\stackrel{0}{I} \\
\underset{I}{A}\end{array}$ & $\begin{array}{l}n \\
0 \\
0 \\
0\end{array}$ & $\begin{array}{l}\infty \\
\stackrel{\infty}{=} \\
=\end{array}$ & $\vec{\sigma}$ & & $\stackrel{+}{\mathbb{t}}$ & $\begin{array}{l}\text { If } \\
\text { fో }\end{array}$ & $\stackrel{+}{m}$ & 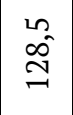 & $\begin{array}{l}+ \\
\stackrel{0}{0} \\
=\end{array}$ & $\begin{array}{l}0 \\
\text { is } \\
\infty\end{array}$ & $\vec{\exists}$ & 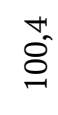 & 今ू \\
\hline \multirow{4}{*}{ 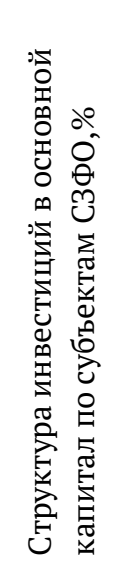 } & 穴 & \& & $\vec{i}$ & के & $\begin{array}{l}0^{0} \\
\infty^{-1}\end{array}$ & & $\begin{array}{l}\hat{\omega} \\
\hat{\omega}\end{array}$ & $\stackrel{0}{+}$ & $\overrightarrow{6}_{0}^{0}$ & $\hat{\sigma}_{\hat{\sigma}}$ & $\overrightarrow{\mathrm{A}}$ & $\tilde{\sigma}^{-}$ & $\hat{\mathrm{i}}$ & $\stackrel{\sharp}{\leftrightarrows}$ & $\begin{array}{l}\hat{\sigma} \\
\text { mे }\end{array}$ \\
\hline & 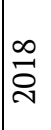 & ¿ & $\underset{\sim}{\approx}$ & $\Rightarrow$ & $\stackrel{+}{\rightleftarrows}$ & & in & $\begin{array}{l}\infty \\
\text { in }\end{array}$ & $\stackrel{M}{\sim}$ & $\hat{\sigma}^{\circ}$ & $\begin{array}{l}\hat{\sigma} \\
\underline{-}\end{array}$ & $\hat{0}^{-}$ & $\begin{array}{l}\infty \\
m^{-}\end{array}$ & $\stackrel{0}{-}$ & $\begin{array}{c}\hat{n} \\
\hat{m}\end{array}$ \\
\hline & 공 & $\stackrel{-}{\circ}$ & $\stackrel{\circ}{i}$ & $\stackrel{\stackrel{n}{\prime}}{=}$ & $\hat{\sigma}^{\prime}$ & & $\stackrel{\sigma_{f}}{ }$ & $\stackrel{\infty}{+}$ & రి & $\overrightarrow{\text { in }}$ & $\begin{array}{l}\hat{n} \\
\text { in }\end{array}$ & $\stackrel{g}{+}$ & $\stackrel{n}{+}$ & $\stackrel{0}{-}$ & $\begin{array}{l}\hat{~} \\
\text { mे }\end{array}$ \\
\hline & $\underset{\sim}{0}$ & \& & $\stackrel{m}{\sim}$ & $\stackrel{\infty}{=}$ & 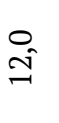 & & $\begin{array}{l}0 \\
\infty \\
\infty\end{array}$ & $\stackrel{\circ}{+}$ & $\overrightarrow{6}$ & $\mid \begin{array}{l}\infty \\
+\end{array}$ & in & $\stackrel{0}{\stackrel{2}{n}}$ & $\stackrel{\infty}{\mathbb{r}^{-}}$ & $\Leftrightarrow$ & $\begin{array}{c}0 \\
\stackrel{m}{m} \\
m\end{array}$ \\
\hline \multirow{4}{*}{ 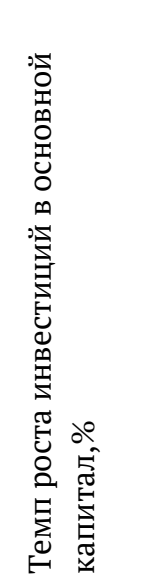 } & 穴 & $\tilde{8}$ & $\begin{array}{l}m \\
8 \\
0\end{array}$ & $\vec{\infty}$ & 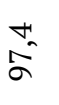 & & $\begin{array}{l}0 \\
\dot{0} \\
0\end{array}$ & $\begin{array}{l}0 \\
\stackrel{\infty}{\infty}\end{array}$ & $\begin{array}{l}\hat{\sigma} \\
\text { స్త }\end{array}$ & $\begin{array}{l}4 \\
\stackrel{n}{6}\end{array}$ & $\begin{array}{c}m \\
\text { aid } \\
\infty\end{array}$ & $\hat{a}$ & $\stackrel{0}{-\infty}$ & 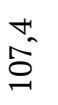 & $\begin{array}{c}\text { Na } \\
\infty \\
\infty\end{array}$ \\
\hline & $\underset{\sim}{\infty}$ & $\begin{array}{l}0 \\
\text { î }\end{array}$ & $\begin{array}{l}\infty \\
10 \\
=\end{array}$ & $\stackrel{\hat{\sigma}}{\hat{0}}$ & $\begin{array}{l}\stackrel{0}{a} \\
\text { à }\end{array}$ & & 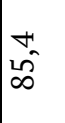 & $\begin{array}{l}n \\
\infty \\
\infty\end{array}$ & $\stackrel{0}{\stackrel{\Xi}{\Xi}}$ & $\begin{array}{l}0 \\
\text { â } \\
\text { I }\end{array}$ & $\stackrel{+}{\stackrel{*}{n}}$ & 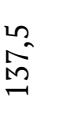 & बेे & $\begin{array}{l}\hat{\sigma} \\
\hat{\theta}\end{array}$ & $\mid \begin{array}{l}\hat{\sigma} \\
\stackrel{\hat{\jmath}}{=}\end{array}$ \\
\hline & 공 & $\overrightarrow{0}$ & $\begin{array}{l}\infty \\
\varrho \\
=\end{array}$ & $\begin{array}{l}0 \\
15 \\
6\end{array}$ & $\begin{array}{l}\text { Na } \\
\text { స̃ }\end{array}$ & & $\begin{array}{l}\stackrel{+}{A} \\
\underset{J}{J}\end{array}$ & $\overrightarrow{\mathrm{m}}$ & $\overrightarrow{\vec{I}}$ & $\begin{array}{l}\infty \\
\dot{q}^{-} \\
\end{array}$ & $\begin{array}{l}\infty \\
\text { 今 } \\
\text { I }\end{array}$ & $\begin{array}{l}\text { In } \\
\text { N̂} \\
\text { Î }\end{array}$ & $\begin{array}{l}0 \\
8\end{array}$ & $\begin{array}{l}\text { m } \\
\text { 今- } \\
-\end{array}$ & $\vec{a}$ \\
\hline & $\stackrel{0}{\stackrel{\sim}{\sim}}$ & $\stackrel{\overbrace{}}{-}$ & $\begin{array}{l}0 \\
0 \\
0\end{array}$ & $\begin{array}{l}\infty \\
\triangleq \\
=\end{array}$ & $\underset{\sigma}{+1}$ & & $\begin{array}{l}\infty \\
\stackrel{+}{*}\end{array}$ & $\vec{q}$ & $\stackrel{O}{\stackrel{O}{M}}$ & 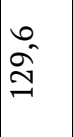 & $\begin{array}{l}0 \\
\stackrel{0}{=} \\
=\end{array}$ & $\vec{\infty}$ & $\begin{array}{l}0 \\
\stackrel{n}{=}\end{array}$ & $\hat{\sigma}$ & $\begin{array}{l}\forall \\
\text { Oे } \\
\text { In }\end{array}$ \\
\hline & 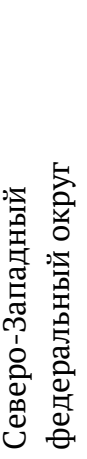 & 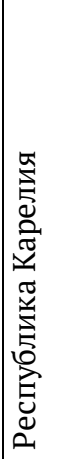 & 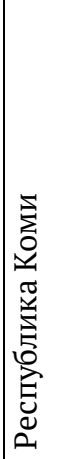 & 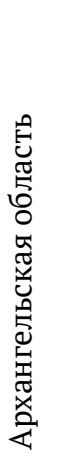 & 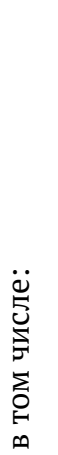 & 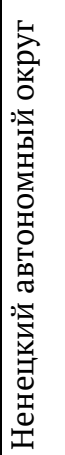 & 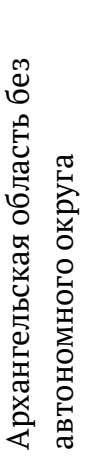 & 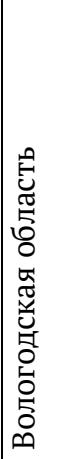 & 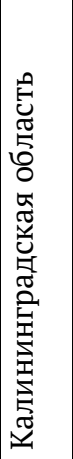 & 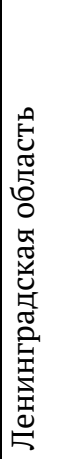 & 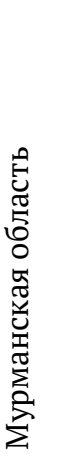 & 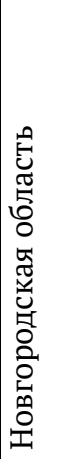 & 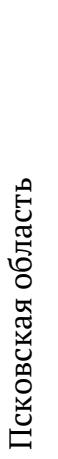 & 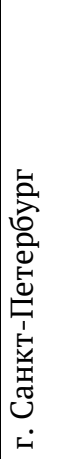 \\
\hline
\end{tabular}

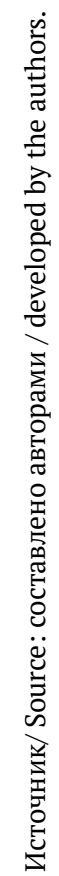


Таблица 5. продолжение / Table 5. continued

\begin{tabular}{|c|c|c|c|c|c|c|c|c|c|c|}
\hline \multirow[t]{2}{*}{ Показатель } & \multicolumn{5}{|c|}{$\begin{array}{c}\text { Доля инвестиций в основной } \\
\text { капитал в ВВП(ВРП), \% }\end{array}$} & \multicolumn{5}{|c|}{$\begin{array}{c}\text { Коэффициент износа основных } \\
\text { средств, \% }\end{array}$} \\
\hline & 2014 & 2015 & 2016 & 2017 & 2018 & 2015 & 2016 & 2017 & 2018 & 2019 \\
\hline Российская Федерация & 20,8 & 20,0 & 21,3 & 21,4 & 20,0 & 47,7 & 48,1 & 47,3 & 46,6 & 37,8 \\
\hline $\begin{array}{l}\text { Северо-Западный федеральный } \\
\text { округ }\end{array}$ & 23,7 & 20,0 & 22,6 & 23,2 & 25,6 & 45,1 & 44,5 & 43,7 & 44,4 & 34,8 \\
\hline Республика Карелия & 17,5 & 15,4 & 15,0 & 16,5 & 17,2 & 46,1 & 48,0 & 48,1 & 49,6 & 40,3 \\
\hline Республика Коми & 41,5 & 32,2 & 36,6 & 23,3 & 20,5 & 49,6 & 48,4 & 48,8 & 50,6 & 49,3 \\
\hline Архангельская область & 29,1 & 27,4 & 24,9 & 29,7 & 24,2 & 46,8 & 45,3 & 44,9 & 47,6 & 44,6 \\
\hline \multicolumn{11}{|l|}{ в том числе: } \\
\hline Ненецкий автономный округ & 42,2 & 50,4 & 33,6 & 41,2 & 29,8 & 45,9 & 44,7 & 42,7 & 50,4 & 52,5 \\
\hline $\begin{array}{l}\text { Архангельская область без авто- } \\
\text { номного округа }\end{array}$ & 22,1 & 14,4 & 19,7 & 23,3 & 20,9 & 47,3 & 45,6 & 46,4 & 45,8 & 40,9 \\
\hline Вологодская область & 20,6 & 18,2 & 23,9 & 27,2 & 26,3 & 49,8 & 51,8 & 48,8 & 50,1 & 46,8 \\
\hline Калининградская область & 20,3 & 19,7 & 23,2 & 31,2 & 34,7 & 37,7 & 36,8 & 37,1 & 40,5 & 40,0 \\
\hline Ленинградская область & 24,2 & 26,6 & 28,8 & 35,0 & 46,3 & 41,4 & 42,1 & 42,4 & 41,0 & 38,8 \\
\hline Мурманская область & 26,1 & 25,0 & 19,8 & 25,6 & 32,3 & 51,3 & 52,2 & 49,6 & 49,9 & 46,8 \\
\hline Новгородская область & 29,3 & 29,6 & 32,4 & 28,0 & 23,5 & 50,2 & 51,0 & 46,3 & 45,6 & 33,9 \\
\hline Псковская область & 24,1 & 20,2 & 18,7 & 19,3 & 19,1 & 52,1 & 54,1 & 53,0 & 51,3 & 42,5 \\
\hline г. Санкт-Петербург & 19,7 & 14,3 & 18,5 & 17,6 & 20,3 & 40,7 & 39,0 & 38,5 & 38,9 & 25,0 \\
\hline
\end{tabular}

ДОЛГОВОЕ ФИНАНСИРОВАНИЕ КАК ФАКТОР СТИМУЛИРОВАНИЯ ИНВЕСТИЦИОННОЙ АКТИВНОСТИ

В целом сравнительный анализ индикаторов позволяет сделать вывод о снижении уровня инвестиционной активности за последние десять лет как в регионах СЗФО, так и в РФ в целом. При этом некоторые российские ученые на протяжении ряда лет отмечают необходимость увеличения инвестиционных вложений в России как основного фактора стимулирования экономического роста" [13, С.793; $1 ; 14]$. Российский экономист, академик РАН, Аганбегян А. Г. полагает: «... без принудительного увеличения инвестиций до уровня 5 трлн. руб. в течение следующих нескольких лет годы станут годами застоя» $[14$, C.11]. Также в его научной работе отмечается, что инвестиции играют двойственную роль в обеспечении экономического роста: в первые периоды вложения в основной капитал вызывают активизацию экономической деятельности, а затем, в среднесрочной перспективе (5 лет и более) экономика получает повторный стимул к росту производства товаров и услуг на базе вновь созданных фондов.
В этой связи заслуживает внимания исследование Маковецкого М.Ю., посвящённое вопросам выявления зависимостей между факторами накопления инвестиций и показателями экономического роста [1]. На базе проведения корреляционно-регрессионного анализа автором доказано, что факторы динамики инвестиционной активности играют первостепенную роль в обеспечении экономического роста [1, C.61]. На базе оценки динамики индекса валового накопления основного капитала за период с 1990 по 2005 гг. в сопоставлении с темпами прироста ВВП в постоянных ценах в статье обосновано, что несмотря на устойчивый рост уровня инвестиций в абсолютном выражении за анализируемый период валовое накопление основного капитала значительно снижается (от 100\% в 1990 г. до 33,4\% в 2005 г.)

Наряду с этим в зарубежных исследованиях также эмпирически подтверждается взаимосвязь между инвестициями и экономическим ростом. Например, в исследовании Азама М. (Azam) Relationship доказано, что чистый приток иностранных инвестиций и экономический рост имеют значительную положительную вза-

\footnotetext{
* Ведев А.Л, Березинская О.Б., Щелокова Д.В.Возможности активизации инвестиционного процесса в экономике России с учетом региональных аспектов его развития. Научно-исследовательская работа URL: https:// papers.ssrn.com/sol3/papers.cfm?abstract_id=3347565
} 
имосвязь для развивающихся стран (Бразилия, Индия, Китай, Южная Африка), что подразумевает повышенный уровень притока инвестиций, который будет способствовать увеличению экономического роста. Базой исследования послужили макроэкономические данные по странам БРИКС за период с 1981 по 2005 год [15, С.34398]. Исследование Мустафакулова Ш. (Mustafakulov) подтверждает гипотезу о том, что связи между инвестиционным потенциалом и экономическим ростом, различны для стран, находящихся на разных стадиях экономического развития [16].

В этом контексте интересным является результаты научной работы Мудацу А. (Moudatsou), подтверждающие наличие дифференцированного эффекта на экономический рост в странах Евросоюза, которые отличаются уровнем производственного, экономического и финансового потенциала. [17, С.697]. В исследовании определено, что более сильный эффект на рост ВВП страны оказывает увеличение инвестиционной активности в менее экономически развитых странах Евросоюза таких как Греция, Италия, Португалия. И, наоборот, страны с более высоким уровнем макроэкономического развития такие как Германия, Австрия, Швеция имеют незначительный эффект от прироста уровня инвестиций в основной капитал страны. Такая зависимость, на наш взгляд, может объяснятся эффектом интеграции, т.е. укреплением связей крупных компаний на внутреннем рынке Евросоюза и расширением границ сбыта продукции. В этом случае увеличение уровня инвестиций в экономике развивающихся стран ЕС отражает получение новых технологий и опыта в результате расширения доли рынка транснациональных корпораций, что способствует значительной модернизации местного производственного потенциала и усиливает эффект на макроэкономические показатели страны.

Поскольку необходимость стимулирования инвестиционной активности не вызывает сомнений, в качестве меры по увеличению инвестиций в основной капитал региона авторы предлагают использовать механизм инвестиционного государственного кредита. Во-первых, одной из приоритетных задач государства является поддержание определенного уровня предпринимательской активности в стране в том числе и за счет сбалансированной кредитнойденежной политики. Во-вторых, использование механизма государственного долгового финан- сирования бюджетов регионов не для покрытия дефицита бюджета, а для увеличения инвестиций в основной капитал в последствии послужит важным фактором увеличения доходов регионального бюджета. Более того, использование долговых инструментов для привлечения инвестиций в результате будет способствовать снижению долговой зависимости бюджетов субъектов РФ в долгосрочной перспективе за счет увеличения числа конкурентоспособных предприятий в стране, повышения занятости населения и др.

В работах российских ученых подчеркивается существенная роль долгового финансирования инвестиционной деятельности и определяется тезис «Если раньше экономика в основном финансировалась за счет внешних рынков капитала, то в настоящее время внутренний долговой рынок должен стать основным источником финансирования». В поддержку этого тезиса говорят результаты исследования Акьюлова Р.И., Алферьева К.А., в котором выявлена обратно пропорциональная зависимость между уровнем инвестиционной активности в регионе и темпами роста долговых обязательств, а также обосновано: «в регионах с самой высокой инвестиционной активностью самые низкие темпы роста долговых обязательств» [18]. В исследовании другого российского ученого доказано, что увеличение доли инвестиционных расходов в бюджетах субъектов Российской Федерации способствует увеличению собственных доходных поступлений и наращиванию собственного экономического потенциала [19].

При этом, результаты исследования, проводимого одним из авторов показали, что взвешенная долговая политика в двух регионах СЗФО (Санкт-Петербург и Ленинградская область) способствует стимулированию инвестиционной активности [10]. Такой вывод можно сделать из сравнения индикаторов долговой устойчивости таких как отношение государственного долга к валовому региональному продукту и уровню госдолга к годовому объему доходов бюджета и темпа роста инвестиций в основной капитал в динамике по каждому региону СЗФО. В исследовании определено, что регионы с высоким качеством управления региональными финансами имеют более высокие темпы роста инвестиций в основной капитал и демонстрируют умеренный прирост доли инвестиций в ВРП на протяжении ряда лет. 
Заслуживающим внимания является исследование Международного валютного фонда «Повышая эффективность госинвестиций», проведенное в 2015 году*. Используя квартальные панельные данные по 114 странам за период 1970-2013 годы была оценена модель зависимости темпов роста ВВП (разность логарифмов ВВП) от доли инвестиций в ВВП с учетом эффективности инвестиций в отдельные годы по разным странам. Согласно данному исследованию, при повышении уровня эффективности управления госинвестициями за счет стимулирования реального сектора экономики отдача от них возрастает в два раза. Таким образом, использование государственного кредитования для стимулирования инвестиционной активности является необходимым и научно обоснованным методом повышения уровня инвестиций в региональной экономике.

\section{ОБЩИЙ ВЫВОД}

В целом по результатам проведенного исследования инвестиционной активности в России в целом и по регионам СФЗО можно сделать вывод о снижении ее уровня за последние десять лет. При этом, этот процесс происходит на фоне роста долговых заимствований в стране. Такое сопоставление дает возможность понять, что средства от размещения государственных долговых обязательств в малой степени направляются на стимулирование инвестиционной активности, в следствие чего, можно сделать вывод об отсутствии инвестиционного стимулирования экономического роста.

Анализ индикаторов инвестиционной активности регионов СЗФО показал, что взвешенная инвестиционная политика властей способству- ют увеличению инвестиционной активности прежде всего в городе Санкт-Петербурге и Ленинградской области. Что качественно выделят эти два региона Северо-запада среди остальных. При этом низкий уровень инвестиционной активности выявлен в Республике Карелия, Архангельской, Калининградской, Новгородской областях. Псковскую область стоит выделить отдельно, как регион с самым низким уровнем инвестиционной активности в сочетании с высоким уровнем государственного долга и кредитного риска.

В процессе исследования проведена систематизация работ российских ученых, посвящённых проблемам увеличения инвестиционной активности, а также взаимосвязи денежнокредитной политики государства и инвестиционного климата в стране. Выявлено, что научных трудах на протяжении ряда лет отмечается необходимость увеличения инвестиций в России как основного фактора стимулирования экономического роста. Анализ зарубежных публикаций показал, что ученые эмпирически доказали сильную связь между уровнем инвестиционной активности и экономическим ростом, и, наряду с этим подтверждают гипотезу о том, что эти связи различны для стран, находящихся на разных стадиях развития экономики. В работе обоснована необходимость использования внутреннего долгового рынка для увеличения инвестиций в основной капитал. Полученные результаты определили выбор меры по стимулированию инвестиционной активности в регионах СЗФО, а именно использование механизма инвестиционного государственного кредита, эффективность которого имеет высокую степень научной обоснованности.

\section{Библиографический список}

1. Маковецкий М. Ю. Инвестиции как ключевой фактор экономического роста. Финансы и кредит. $2007 ; 242$ (2):8-17.

2. Трынов А.В. Теоретические аспекты анализа инвестиционного потенциала региона в разрезе институциональных секторов. Журнал экономической теории. 2020; 17(1): 238-244

3. Fadeeva A.Ju. Information and communication technologies as a development driver of regions investment attractiveness. Russian Journal of Industrial Economics. 2017; 10(4):377-386. DOI: 10.17073/2072-1633-20174-377-386

4. Окрепилов В. В., Гагулина Н. Л. Развитие оценки качества жизни населения региона. Журнал экономической теории. 2019; 16(3): 318-330.

5. Игонина Л. Л. Финансовый потенциал инвестиционного процесса в российской экономике. Финансы и кредит. 2016; 238 (2): 2-14.

\footnotetext{
* Making public investment more efficient. Staff Report of IMF. June 11, 2015. Brochure. Available at: https://www.imf. org/external/np/pp/eng/2015/061115.pdf
} 
6. KiselevaE.G. The impact of digital transformation on the investment potential of the Russian cities. Finance: Theory and Practice. 2020; 24(5); 72-83. DOI: 10.26794/2587-5671-2020-24-5-72-83

7. Уткин Б.Е. Динамика инвестиций в основной капитал ведущих стран мира. Экономическая теория. 2016; 134(1): 14-19.

8. Krasilnikova E. A., Mayorova E. A., Nikishin A.F., Pankina T.V. Investment activities in Russia's regions. European Research Studies Journal. 2017; XX(4B): 509-521

9. Капранова Л.Д. Развитие региональной инвестиционной политики в Северо-западном федеральном округе. Финансовая аналитика: проблемы и решения. 2011; 62(20): 23-30.

10. Гончарук О.В., Киселева Е.Г. Индикативное управление устойчивостью региональных финансовых систем как фактор обеспечения стабильного экономического роста // Стратегическое планирование и развитие предприятия: материалы XXII Всероссийского симпозиума. Москва: ЦЭМИ РАН, 2021; (4) 359-361. DOI: 10.34706/978-5-8211-0796-1-s4-27

11. Сангинова Л.Д. Эффективная долговая политика субъектов Российской Федерации: теория и практика. Экономика. Налоги. Право. 2018; 11(1): 96-105. DOI: 10.26794/1999-849X-2018-11-1-96-105

12. Киселева О.В. Инвестиционная активность регионов Российской Федерации. Вестник университета. 2012; (10): $38-45$.

13. Капранова Л.Д. Основные направления финансовой поддержки инвестиционной активности и экономического роста в регионах России. Региональная экономика: теория и практика. 2018; 16 (5): $792-804$

14. Аганбегян А.Г. О Неотложных мерах по возобновлению социально-экономического роста. Проблемы прогнозирования. 2019; (1): 3-15. URL: https://cyberleninka.ru/article/n/o-neotlozhnyh-merah-povozobnovleniyu-sotsialno-ekonomicheskogo-rosta (дата обращения: 10.05.2021).

15. Azam M. Relationship between energy, investment, human capital, environment, and economic growth in four BRICS countries. Environmental Science and Pollution Research. 2019; 33(26): 34388-34400. DOI: 10.1007/ s11356-019-06533-9

16. Mustafakulov Sh. I. Investment Attractiveness of Regions: Methodic Aspects of the Definition and Classification of Impacting Factors. European Scientific Journal. 2017; 13(10): 433-449. DOI: 10.19044/esj.2017.v13n10p433.

17. Moudatsou A. Foreign Direct Investment and Economic Growth in the European Union. Journal of Economic Integration. 2003; 18 (4): 689-707

18. Акьюлов Р. И., Алферьев К. А. К вопросу о взаимосвязи инвестиционной активности и долговых обязательств российских регионов. Вопросы управления. 2017; 1 (44): 90-95.

19. Солдаткин С.Н. Эффективность региональной долговой политики через призму инвестиционной активности. Региональная экономика: теория и практика. 2015; (30):46-57. 14

20. Nicholls J. Social return on investment - Development and convergence. Evaluation and Program Planning. 2017; 64 (1): 127-135. DOI: 10.1016/j.evalprogplan.2016.11.011 